\title{
EL CONTRATO COLONIAL Y LA FUNDACIÓN DE LA REPÚBLICA PERUANA: UN ANÁLISIS DECOLONIAL
}

\author{
THE COLONIAL CONTRACT AND THE FOUNDATION OF THE \\ PERUVIAN REPUBLIC: A DECOLONIAL ANALYSIS \\ Jonathan Riveros Ramos ${ }^{1 *}$ \\ jonathan.riveros@unmsm.edu.pe \\ ${ }^{1}$ Universidad Nacional Mayor de San Marcos, Lima, Perú,
}

* Correspondencia: Jonathan Riveros Ramos. Email: jonathan.riveros@unmsm.edu.pe

Recibido: 16.0821 | Aprobado: 06.09.21

\section{RESUMEN}

El presente artículo se centra en analizar la relación que existe entre el contrato colonial y la fundación de la República del Perú, centrándose en categorías claves como el racismo, capitalismo, patriarcalismo y eurocentrismo desde la filosofía decolonial. El objetivo es demostrar la relación que existe entre el Contrato colonial y la fundación de la República Peruana para entender los problemas filosóficos, políticos, económicos, sociales y epistémicos que atraviesa el Perú en el siglo XXI. El presente trabajo es de investigación filosófica y documentaria, con método analéctico y genealógico el cual nos permitirá entender desde una geopolítica del conocimiento no eurocentrada las bifurcaciones y la configuración que ha tenido la teoría del contrato social en la fundación del Perú. La importancia del presente trabajo nos permitirá comprender cómo operan las relaciones de dominación del contrato colonial en el Perú del siglo XXI.

Palabras Claves: Modernidad, Colonialidad, Contrato Colonial, República del Perú.

\begin{abstract}
This article focuses on analyzing the relationship between the colonial contract and the founding of the Republic of Peru, centering on key categories such as racism, capitalism, patriarchalism and eurocentrism from the decolonial philosophy. The objective is to demonstrate the relationship that exists between the Colonial Contract and the foundation of the Peruvian Republic to understand the philosophical, political, economic, social and epistemic problems that Peru is going through in the XXI century. The present work is of philosophical and documentary research, with an analectic and genealogical method which will allow us to understand from a geopolitics of knowledge that is not eurocentric, the bifurcations and the configuration has had the social contract theory in the founding of Peru. The importance of the present work will allow us to understand how the relations of domination of the colonial contract operate in Peru in the XXI century.
\end{abstract}

Keywords: Modernity, Coloniality, Colonial Contract, Republic of Peru. 


\section{INTRODUCCIÓN}

El desarrollo histórico del Perú en los últimos doscientos años como república independiente pone en evidencia una serie de problemas históricos irresueltos como el clasismo, la desigualdad, el racismo, la violencia feminicida, la dependencia cultural, entre otros, dichos problemas estructurales se encuentran incrustados desde la invasión española y la posterior colonización que es el momento fundante para la modernidad y las lógicas civilizatorias de Occidente en el nuevo mundo y el Perú. Con el desarrollo de la modernidad, la expansión de Occidente a través de la colonización, la institución del Estado-nación se estableció como máxima institución política por antonomasia, dicha institución política se expandió tanto por Europa como en el mundo no europeo, suprimiendo otras instituciones políticas como el Sultanato en el mundo musulmán, la dinastía en China, el Tawantinsuyo en el Perú, por mencionar algunos (Grosfoguel y Mignolo, 2008b), constituyéndose así el de Estado-nación, como única institución política moderna.

El Estado-nación es la primera institución política de la modernidad, dicha invención se creó en 1492, siendo España el primer Estado-nación moderno y desde sus orígenes fue excluyente, su estructura obedeció a una población mayoritaria, una religión, una lengua y un poder político centralizado, elementos que han creado tensiones en todos los Estados del mundo moderno (Dussel, 2000; 2015) y del cual el Perú no es excepción. El fundamento filosófico y político del Estado-nación es la teoría del contrato social, que es un artificio filosófico para justificar el ordenamiento social y la dominación de los "otros", el cual comprende a todos los sujetos subalternizados, invisibilizados y exterminados por la modernidad en el mundo periférico (Montañez, 2015). Al respecto, Lepe Carrión (2016) sostiene:

La visión rousseauniana de un supuesto Estado como pacto, entre un pueblo y sus mandatarios, fundado en la 'convención' y no en la 'naturaleza', intenta mostrar el contrato como un acto 'puro', libre de contradicciones o luchas internas de poder y de violencia, o exenta de voluntades despóticas en el sometimiento de los más débiles (p. $325)$.

El presente trabajo sostiene que, tanto en el Perú como América Latina, el contrato social ha operado como un contrato colonial, el cual tiene su fundamento histórico filosófico en el establecimiento de la Modernidad y el colonialismo, implantados desde el siglo XVI y que continúa aún en el siglo XXI como colonialidad, asimismo, tiene como partes integrantes, un contrato racial, capitalista y sexual y que están avalados por la dominación epistémica occidental que es el eurocentrismo. El contrato colonial ha operado en un primer momento bajo el dominio del colonialismo europeo y más tarde por sus descendientes, los criollos en la fundación de las repúblicas "independientes" en el continente americano.

Analizando el contrato social en el Perú, se señala el carácter colonial de este en la fundación de la república peruana, el cual ha incidido en la desestructuración histórica como Estado, sociedad, ciudadanía, dividiendo el país en dos mundos, uno en el cual las élites blancas, burguesas, racistas, patriarcales, citadinas, eurocéntricas, gobiernan y el otro el resto del Perú que representa el mundo inferiorizado, (mestizos, indígenas, 
afrodescendientes y mujeres), en otros términos, es una versión aggiornada de lo que fue la república de españoles e indios que caracterizó el período colonial (Lynch, 2014). En esta nueva sociedad moderno/colonial, en términos parmenidianos el ser, ahora es el español, portador de la religión verdadera, ciencia, cultura y civilización, mientras que el no-ser es el indígena, el mestizo, el africano y la mujer, ahora sumidos a la servidumbre, el esclavismo, como los bárbaros a evangelizar, educar, civilizar, desarrollar, democratizar, vale decir, a occidentalizarlos (Dussel, 1980; Grosfoguel, 2008a).

El presente trabajo se propone a reflexionar la naturaleza del contrato colonial, para dicha empresa se emplea el método genealógico y analéctico, el método genealógico propuesto por Foucault (2004) permite entender el origen, mutación y devenir de la teoría contractual en la fundación de la república peruana, asimismo el método analéctico propuesto por Dussel (1980) permite analizar la posicionalidad del otro como sujeto negado, invisibilizado y exterminado en la teoría contractual y cuestionar los límites de la modernidad política en la fundación de la república peruana.

\section{FILOSOFÍA, MODERNIDAD Y COLONIALIDAD}

Reflexionar la filosofía política desde el contexto latinoamericano, es una tarea que muy poco se ha hecho y esto como producto de la situación de dependencia estructural de la región tanto a nivel económico, político, social, cultural, epistémico, entre otros, lo que ha creado una alienación teórica, que se manifiesta en una receptividad pasiva y el imitacionismo de las teorías occidentales, privándonos de construir una teoría genuina que pueda repensar nuestros problemas (Salazar, 1995). Es menester por lo tanto repensar la filosofía política en Latinoamericana desde nuestro contexto, sin repetir dogmáticamente los postulados de la modernidad occidental pero tampoco rechazarla a priori, sino crear una filosofía política propia, en otras palabras, una filosofía que este centrada en el contexto del cual podamos crear paradigmas, categorías y conceptos que nos puedan ayudar a entender mejor nuestra realidad (Auat, 2011).

La investigación filosófica con perspectiva decolonial se centra en analizar el lado negativo de la impronta de la modernidad, vale decir, la colonialidad que comprende todas las relaciones de dominación del sistema mundo /moderno colonial o civilización occidental que es constitutiva a la modernidad y que se manifiesta en el mundo periférico, excluyendo a los otros no europeos/occidentales que son negados, invisibilizados y exterminados pero que han resistido a los embates de la colonización surgiendo un pensamiento reflexivo y de resistencia desde los excluidos del sistema que son la exterioridad de la totalidad del sistema (Alvarado, 2017; Grosfoguel, 2006; Dussel, 1980).

La filosofía decolonial representa el pensamiento crítico latinoamericano en el siglo XXI, porque cuestiona los presupuestos civilizatorios de Occidente y forma parte de las epistemologías del Sur que comprende los conocimientos de los pueblos originarios, pueblos oprimidos, colonizados, países subdesarrollados y que forman parte del sur global (De Sousa y Meneses, 2014). La descolonización es una agenda no resuelta en el siglo XXI, no es un tema que solo atañe a América Latina, sino a todo el mundo periférico que representa la gran materia de población mundial, que es racializada, empobrecida y saqueada y que hoy forma parte de la categoría de Tercer Mundo (Maldonado-torres, 2008). Al respecto Grosfoguel (2006) sostiene: 
Con la descolonización jurídico-política pasamos de un periodo de «colonialismo global» al actual periodo de «colonialidad global». Aunque las «administraciones coloniales» han sido erradicadas casi por completo y la mayor parte de la periferia está organizada políticamente en Estados independientes, los no europeos siguen viviendo bajo la cruda explotación y dominación europea/euroamericana (p. 28).

La filosofía política mainstream que se imparte en todos los centros de enseñanza es la manifestación histórica provincial del continente europeo en los últimos tres milenios, constituido en la entidad denominada Occidente, el cual comprende tanto Europa como los Estados Unidos y que representa el centro hegemónico del planeta desde hace quinientos años, mientras que América Latina, África, Asia y Oceanía se han constituido como periferias globales. Debido a la condición subalterna hemos asimilado la epistemología occidental como el único conocimiento válido para explicar todos los campos del saber, sobre todo en la Filosofía, la Ciencia Política, el Derecho que son importantes para entender la teoría del contrato social y de los fundamentos de la República. Al respecto, Dussel (2015) critica el mito eurocéntrico de la Filosofía y sostiene:

[...] queremos indicar claramente ni la filosofía nació sólo ni primeramente en Grecia (en el tiempo). Ni puede tomarse a ésta como prototipo del discurso filosófico (por su contenido). De allí el error de muchos que en vez de describir los caracteres que deben definirse como criterios de demarcación entre el mito y el discurso categorial filosófico tiende a tomar a la filosofía griega como la definición misma de la filosofía en cuanto tal. Esto es confundir la parte con el todo: un caso particular no incluye la definición universal. [...] Esto produce un fenómeno de ocultamiento y distorsión en la historia que denominamos heleno y euro-centrismo e impedirá tener una visión mundial de lo que realmente ha acontecido en la historia de la filosofía (pp. 18-19).

Para los teóricos decoloniales, la producción del conocimiento está situada y posee un contexto específico, desde el cual se hace un locus de enunciación, la filosofía occidental se posiciona desde la geopolítica del eurocentrismo y se presenta como universal abstracta sin tiempo y espacio como un Deus Absconditus que lo observa todo desde un altar invisible a los ojos de todos, mientras que desde Latinoamérica se construye una geopolítica del conocimiento alternativo al pensamiento dominante (Mignolo, 2015; Castro-Gómez, 2007). Asimismo, la categoría de corpo-politica nos indica que el conocimiento no está descorporalizado, esta influenciado por los sujetos que lo producen, las experiencias sociales, las historias de vida marcan el percorso del pensamiento, esta puede ser una corporalidad blanca-occidental como también cuerpos racializados, cada una de ellas marcará el límite de su conocimiento en base a su experiencia social (Restrepo, 2016; Grosfoguel, 2006).

La filosofía es una actitud de reflexión de la totalidad de la experiencia humana de los pueblos sobre su presencia en el cosmos, asimismo está ligado a las relaciones sociales y al contexto donde se origina, la actividad de la filosofía no es exclusividad de un pueblo elegido o espacio privilegiado como nos hace creer la filosofía occidental (Dussel, 2015). Analizando históricamente las raíces de la filosofía occidental, estas se encuentran en el 
helenocentrismo (mundo griego) y el judaísmo (mundo judío) (Aguilar, 2018) que pertenece a una realidad local europea, pero que tiene pretensión universal gracias a la expansión de la modernidad/colonialidad (Mignolo, 2015).

La filosofía política como cualquier actividad humana y cultural de cada pueblo siempre ha estado permeada por las relaciones de poder, de ahí que el saber filosófico no se pueda entenderse sin la relación con el poder, constituyéndose lo que Foucault (2019) denominó el régimen y la política general de la verdad, que se manifiesta en sus discursos, mecanismos, técnicas y procedimientos para legitimar lo "verdadero" y vigilar sancionar lo que es "falso", parafraseando al filósofo francés, estaríamos dentro del régimen de verdad occidental que permea todas las áreas del conocimiento en el planeta.

La filosofía moderna inicia con la modernidad, que es el proceso histórico de apertura de Europa hacia el Atlántico, producto del cercamiento del mundo musulmán y del afán de expandir las rutas comerciales con China e India lo que provocó grandes transformaciones para Europa y el mundo en el siglo XVI, entre ellas la invasión del continente americano en 1492 y la posterior colonización del planeta y el nacimiento de filosofía moderna (Dussel, 2005), asimismo, la modernidad fue un proyecto civilizador llevado a cabo por Europa hacia el resto del mundo que originó lo que hoy llamamos civilización occidental con una multiplicidad de relaciones de dominación moderna (Grosfoguel, 2016) y del cual la filosofía no está exenta. Al respecto, Dussel (2015) sostiene:

La filosofía moderna europea aparecerá a sus propios ojos, entonces, y a los de las comunidades de intelectuales de un mundo colonial en extrema postración, paralizado filosóficamente, como la filosofía universal. Situada geopolítica, económica y culturalmente en el centro, manipulará desde ese espacio privilegiado la información de todas las culturas periféricas (pp. 22-23).

Con el "descubrimiento" del nuevo mundo, Europa inició la era de la colonización global que condicionó el devenir histórico de los territorios conquistados, vale decir, el mundo no-occidental, en esta empresa de conquista mundial, la filosofía política no fue ajena al proceso histórico global de colonización, es menester mencionar que la colonización inició con los imperios ibéricos Portugal y España, conocido también como la modernidad temprana (Dussel, 2007), que permitió la salida hacia el océano atlántico, con el objetivo buscar nuevas rutas comerciales para llegar a Asia.

El proyecto de la colonización fue dirigido por la naciente burguesía europea que se presentó como una nueva clase social ascendente en toda Europa y que rediseñó el mundo en los próximos cinco siglos, lo que hoy conocemos como civilización occidental o sistema mundo moderno/colonial (Grosfoguel, 2006), teniendo como eje de dominación Occidente sobre el mundo no-occidental. "No existe «civilización occidental» antes de la expansión colonial europea. La «modernidad» es la civilización que se crea a partir de la expansión colonial europea en 1492 y que se produce en la relación de dominación de «Occidente» sobre «no-Occidente»» (Grosfoguel, 2016, p. 160).

Históricamente la región latinoamericana y el Perú no han reflexionado desde su locus de enunciación, esto como producto de la posición de subordinación que ocupamos 
en la actual civilización moderna y que es legitimado por el eurocentrismo (Dussel, 2015), asimismo, desconocemos nuestra verdadera historia, que es la historia de los vencidos, la barbarie y la miseria (Benjamin, 2008). La relación del saber respecto al poder puede estar también en una posición epistémica de dominación o de resistencia (Grosfoguel, 2006), el presente análisis se encuadra desde la desobediencia epistémica (Mignolo, 2010), el cual cuestiona los fundamentos de la modernidad en la filosofía política respecto al contrato social y la fundación de la república peruana.

La retórica dominante sobre el origen de la modernidad, tiene como fechas fundadoras la invención de la imprenta con Gutenberg (1436), Lutero y la reforma protestante (1520), el tratado de Westfalia (1648), los estallidos de la revolución americana y francesa (1776 y 1789) o Freud y el desarrollo del psicoanálisis y el movimiento del «modernismo» en literatura y bellas artes (1895) (Toulmin, 2001). Desde la geopolítica del conocimiento de América Latina, 1492 representa la fecha que dio inicio a la modernidad (Dussel, 2008a), período histórico en el cuál Europa salió de su posición subordinada en el sistema-mundo respecto a China, India y el mundo musulmán e inició la era del dominio global, a través del "descubrimiento" del nuevo mundo y la posterior colonización del planeta.

La modernidad se presenta con un doble significado, para Europa la modernidad implicó el desarrollo del humanismo, la ilustración, la ciencia, el capitalismo, el desarrollo, la democracia, entre otros, el cual le otorga características positivas, en contraste, la modernidad vista desde el continente americano presenta un dark side, que comprende la violencia y genocidio fundante contra las poblaciones no europeas, de ahí que no hay modernidad sin colonialidad (Mignolo, 2015). Este lado negativo de la modernidad implicó violencia, colonización, esclavitud, patriarcalismo, pobreza, subdesarrollo y autoritarismo en los pueblos no-europeos (Grosfoguel, 2016).

Para entender las relaciones de dominación, empleamos el concepto de colonialidad, término acuñado por (Quijano, 2014), que distingue del concepto de colonialismo, ya que esta última denota la dominación política-legal (la colonia) que ejercieron las potencias europeas en los territorios del "nuevo mundo" y más tarde en otros continentes entre los siglos XVI y XX. Por otra parte, la colonialidad es constitutiva a la modernidad e implica una serie de relaciones de dominación que se manifiestan tanto en el periodo colonial como independiente de los Estados latinoamericanos, entre las dimensiones estudiadas de la colonialidad están la raza (Césaire, 1979), (Fanón, 2009), el poder (Quijano, 2014), el saber (Grosfoguel, 2013), (Walsh, 2008), el ser (MaldonadoTorres, 2007), el ver (Barriendos, 2011), (León, 2012), el capitalismo (Dussel, 2008b), el Estado-nación (Gandarilla y Gómez, 2017), el género (Lugones, 2008), el lenguaje (Veronelli, 2016) el derecho (Garzón López, 2018), la naturaleza (Escobar, 2011), la comida (Albán Achinte, 2010), etc.

La colonialidad opera como una multiplicidad de relaciones de jerarquías de dominación que se dan simultáneamente en el sistema mundo moderno/colonial y van desde el campo político, económico, social, cultural, religioso, espacial, estético, epistémico, de género, entre otros, donde no existe una sola jerarquía de dominación en última instancia como sostenía el marxismo tradicional (la economía), sino que operan en 
una estructura heterárquica, en el cual no puedes comprender una jerarquía de dominación sin las otras, ya que todas son interdependientes, concomitantes, complejas y operan de manera imbricada, el cual funcionan con una lógica dicotómica y excluyente de superioridad e inferioridad de lo humano y no humano en cualquiera de sus categorías de dominación (Grosfoguel, 2006; 2016).

En el contexto del surgimiento de la modernidad, la acumulación capitalista, la colonización, la esclavización y los genocidios/episemicidios (Grosfoguel, 2013), se dieron también los primeros debates sobre la modernidad, es importante mencionar los debates de los filósofos españoles, ya que fueron los primeros en el mundo occidental en discutir las cuestiones políticas y éticas de la naciente filosofía política moderna, el derecho a la conquista, la colonización y la naturaleza del indio, la otredad, los derechos humanos, el contrato social y el Estado como institución política por antonomasia del mundo moderno/colonial serán centrales en la discusión filosofía tanto en Europa como en América, en este periodo destacaron brillantemente los filósofos españoles como De las Casas, Vittoria y Suárez (Dussel, 2005).

Entre los temas estudiados por la naciente filosofía política moderna, está la cuestión de la otredad del indígena y la teoría del contrato social que son fundamento para la construcción política de la república peruana. La cuestión del otro, o la otredad es un tema importante porque permite comprender las dinámicas de la dominación occidental sobre las poblaciones originarias, mestizas, afrodescendientes, entre otros y que son racializadas, estratificadas y sexualizadas en el naciente sistema-mundo moderno/colonial (Grosfoguel, 2006; 2016). El momento fundante de la modernidad se da en el continente americano en 1492, donde Europa se reconoce como sujeto histórico que somete, niega e invisibiliza a los otros, de la negación a la alteridad, Europa se arroja el derecho de dominar, pensar, interpretar y clasificar a los otros (Dussel, 2008a).

Europa ha constituido a las otras culturas, mundos, personas como objeto: como lo "arrojado" (-jacere) "ante" (ob-) sus ojos. El "cubierto" ha sido "des-cubierto": ego cogito cogitatum, europeizado, pero inmediatamente "encubierto" como Otro. El Otro constituido como lo Mismo. El ego moderno "nace" en esta autoconstitución ante las otras regiones dominadas (Dussel, 2008a, p. 36).

El debate sobre la ontología y naturaleza de los no-europeos, en especial las poblaciones indígenas "descubiertas" en el continente americano fueron discutidas en el famoso debate de Valladolid en la Escuela de Salamanca en 1552, dicho debate definió la humanidad y los derechos humanos de todas la poblaciones en el mundo moderno (Wallerstein, 2007), asimismo, se definió la nueva división internacional del trabajo con el racismo como principio organizador del naciente capitalismo (Grosfoguel, 2013).

El debate de Valladolid estuvo a cargo de la Iglesia Católica, institución que por aquellos años tenía el monopolio del conocimiento, por una parte, el teólogo Ginés de Sepúlveda sostenía que los indígenas eran sujetos sin alma y eran bestias, posición que era favorable para su esclavización, para ello se valió también de criterios capitalistas como la ausencia de la noción de propiedad privada y del mercado, por otra parte, De las Casas, concebía a los indígenas como sujetos con alma, pero su naturaleza era de barbarie, de ahí la necesidad de cristianizar para que conozcan al verdadero Dios, por lo tanto los 
indígenas no podían se esclavizados (Grosfoguel, 2013), dicha postura expresa también una posición paternalista que reconoce su humanidad pero incompleta, de ahí la tarea de cristianizar, civilizar, desarrollar y democratizarlos (Ochoa, 2014).

\section{MODERNIDAD Y CONTRATO COLONIAL EN EL PERÚ}

En el Perú, la modernidad llegó con la colonización europea (Quijano, 2014) y tuvo como fecha emblemática 1532, cuando España invade el Tawantinsuyo con la famosa captura del Inca Atahualpa y la posterior destrucción del Tawantinsuyo, dicho acontecimiento significó el choque entre Occidente y el mundo no-occidental, entre la civilización europea y la última civilización en el continente americano (Klarén, 2004), en ese sentido la implantación de la colonia significó el momento fundante de la subordinación del Tawantinsuyo y posteriormente del Perú a las lógicas civilizatorias de Occidente.

El colonialismo creó las condiciones para implantar el contrato colonial a través del genocidio, la servidumbre, la homogenización y otredad de los pueblos originarios y los epistemicidios, elementos que subalternizaron política, económica, cultural y epistémicamente a los pueblos originarios, mestizos, afrodescendientes, entre otros (Montañez, 2015; Grosfoguel, 2013). El contrato colonial, consiste en un conjunto de reglas, normas, reglamentos no escritos que organizan política, económica, social y culturalmente los territorios conquistados por Occidente entre el colonizador y los colonizados y que se institucionalizan tanto en las administraciones coloniales como en los nacientes Estados independientes. Dicho contrato es ejecutado por las élites imperiales en complicidad con las élites locales (occidentalizadas) aplicándose de manera violenta en dichos territorios, dicho contrato sigue estando presente en las sociedades postcoloniales, aun cuando la colonización formal ha terminado, su vigor sigue manifestándose (Benyera, 2020).

En los Estados coloniales/no-occidentales como el Perú, el contrato social adquirió una configuración de contrato colonial en el cual los poderes imperiales y las élites locales colonizadas (europeos mestizos, indígenas) establecieron la jerarquización de la sociedad en base a los derechos de ciudadanía (Thompson, 2000), en el Perú el contrato colonial estratificó a todos los integrantes de la sociedad, estableciendo sujetos con derechos plenos, en el caso de europeos/y descendientes europeos, sujetos con algunos derechos (mestizos) y sujetos sin derechos (africanos), este último grupo es muy emblemático, ya que la independencia del Perú no significó una completa libertad, sino que se tuvo que esperar hasta mediados del siglo XIX en el gobierno de Ramón Castilla para alcanzar la plena libertad (Rubio, 2014).

El contrato colonial tiene como partes integrantes, el contrato racial (Mills, 1997), el contrato capitalista (Marx, 1988), el contrato sexual (Pateman, 1995) y que están legitimados a por la dominación epistémica occidental que se expresa en el eurocentrismo (Quijano, 2014). El contrato colonial ha operado en un primer momento bajo el dominio del colonialismo europeo y más adelante por sus descendientes, los criollos en la fundación de las repúblicas "independientes" en el continente americano, imponiendo una serie de heterarquías de dominación moderno/colonial, garantizando la dominación sobre toda alteridad no europea, en otras palabras, las poblaciones indígenas, mestizos, 
afrodescendientes y mujeres, bajo el pretexto de evangelizar, civilizar, desarrollar y democratizar a estos últimos (Grosfoguel, 2006).

A partir de la invasión española y la posterior colonización del Perú, la sociedad colonial empezó a adquirir características racistas, clasistas, patriarcales y sexistas, eurocéntricas etc., que definirán la futura República del Perú (Quijano, 2014; Lynch, 2014; Mannarelli, 2018; Germana, 2018). En la sociedad moderno/colonial, el ser, se constituyó en el español, portador de la religión verdadera, ciencia, cultura, en esencia, la civilización, mientras que el no-ser es el indígena, el mestizo, el africano y la mujer quedaron sometidos a la servidumbre, el esclavismo, convirtiéndose en los bárbaros a evangelizar, educar, civilizar, desarrollar, democratizar, vale decir, a occidentalizarlos (Dussel, 2008a; Grosfoguel, 2006).

Debemos entender que el contrato social, producto cultural de la civilización europea no funciona sin su correlativo barbárico, que es el contrato colonial, tanto el contrato social como el contrato colonial son diferentes pero complementarias al funcionamiento civilizatorio de Occidente tanto en los centros como en las periferias globales. Al respecto, Benjamin (2008) sostenía: "No hay documento de cultura que no sea a la vez un documento de barbarie. Y así como éste no está libre de barbarie, tampoco lo está el proceso de la transmisión a través del cual los unos lo heredan de los otros" (p. 42).

\section{EL CONTRATO COLONIAL Y EL RACISMO}

Entre las partes integrantes del contrato colonial está el contrato racial, el cual es un conjunto de reglas formales, informales y meta acuerdos que garantizan privilegios y derechos de un grupo dominante, vale decir, las personas blancas (varones y mujeres) respecto a las personas no blancas, estos últimos son considerados sujetos inferiorizados, de ahí la explotación de sus cuerpos, tierras y recursos, negándoles la igualdad de oportunidades socioeconómicas, en ese sentido la teoría del contrato social esconde la naturaleza de la supremacía blanca global del cual la academia occidental nunca lo ha teorizado, por lo tanto es imperativo reflexionar y confrontar a este sistema que opera como una estructura de poder con reglas propias, que tiene una serie de privilegios y ventajas tanto en el campo social, económico como en la distribución de riquezas, oportunidades, beneficios, derechos, deberes, entre otros, concentrándose para un pequeño grupo privilegiado (Mills, 1997).

En el Perú, el racismo es una parte importante del contrato colonial, el cual se fundamenta en la institucionalización de una jerarquía de superioridad e inferioridad respecto a la línea de lo humano que se estableció desde la modernidad occidental, las personas que están arriba de la línea de lo humano, su humanidad es reconocida, y son considerados sujetos de plenos derechos y deberes, mientras que las personas debajo de la línea de lo no humano son considerados sujetos inferiores, como sub-humanos y no humanos, esto significa que su humanidad es cuestionada y negada (Grosfoguel, 2012; Fanon, 2009).

En la historia del Perú, el racismo ha mutado dependiendo a la temporalidad histórica, en el periodo de la invasión europea el primer racismo que se manifestó fue con 
el marcador religioso y cultural que se difundió por todo el periodo de la colonia (Zapata y Rojas, 2013), la identidad religiosa se constituyó como el primer marcador de racismo en Europa anterior a 1492, en el periodo de la llamada "reconquista" de la península ibérica, el conflicto entre españoles cristianos, musulmanes y judíos era un tema importante, en dicho periodo el racismo operó con marcadores religiosos, los judíos y árabes eran consideradas como personas con la religión equivocada (Judaísmo, Islam) mientras que más tarde en la Américas, los indígenas americanos serán catalogados como gente sin religión, gentes sin Dios (Grosfoguel, 2014). Para los españoles, los pueblos no cristianos como los indígenas eran sujetos susceptibles a ser dominados por la fuerza y obligados a cristianizarse (Ochoa, 2014).

El otro marcador de racismo en la colonia fue el cultural, la cual identificaba a los indígenas como bárbaros, vale decir, sujetos carentes de la civilización (leyes, propiedad privada, mercado, escritura, artes, religión monoteísta). La analogía de los indígenas como bárbaros está ligada a la historia de inferiorización de estos últimos en la antigua Grecia. Al respecto, Lepe-Carrión (2016) sostiene:

Ya los griegos hacían uso de la expresión 'bárbaro' ( $\beta \dot{\alpha} \varrho \beta \alpha \varrho o \iota)$, para referirse principalmente a la distinción cultural' (no sanguínea) que acontecía entre ellos y los extranjeros (o al interior mismo de la nación en algunos casos), a los que no eran 'helenos' (E $\lambda \lambda \eta \nu \varepsilon s)$ : a la escasa vida ciudadana (ya sea por su rezago, o por su carácter rudimentario), de un ágora, de la vida gimnástica, de la paideia, o de la participación en los agones (pp. 26-27).

\section{EL CONTRATO COLONIAL Y EL CAPITALISMO}

El contrato capitalista está basado en la relación capital-trabajo de ahí, que se crea una estructura jerárquica entre la burguesía y proletariado, entre los que detentan los medios de producción y los que no lo detentan y tienen que vender su fuerza de trabajo como único medio de subsistencia (Marx, 1988) pero, en la periferia esta dominación se ve agravada no solo por la relación de capital-trabajo sino por otras múltiples jerarquías de dominación como raza, etnia, género, sexo, entre otros, complejizando más las relaciones de dominación capitalista (Quijano, 2014).

El contrato colonial y el capitalismo, tienen como punto de encuentro la invasión del Tawantinsuyo en 1532, el cual introdujo a los andes a la economía capitalista del mundo moderno colonial bajo las lógicas de dominación de esta, creándose un mundo subordinado económicamente a Europa, es decir, América se convierte en la primera periferia capitalista productora de materias primas en el cual el esclavismo, exterminio y explotación de minerales se convierte en los factores fundamentales de acumulación originaria (Marx, 1988).

En América Latina y en especial en México y el Perú se inició el proceso de acumulación originaria del capitalismo europeo, concretamente con el sistema colonial de la explotación de los indígenas y de las materias primas (Marx, 1988), que después se va a expandir por todo el planeta, conformándose un capitalismo central controlado por Europa y más tarde por los Estados Unidos, que explotará a sus colonias (América Latina, Asia, Medio Oriente y Oceanía) y semicolonias como (China e India), las colonias 
aportaron materias primas, manos de obra barata y nuevos mercados integrándose estas dentro del sistema capitalista, pero como economías capitalistas periféricas con modelo primario-exportador, dependientes de los centros globales del capitalismo (Wallerstein, 2005).

La economía que surgió en el virreinato del Perú estaba compuesto por los estratos sociales que la componían, por una parte, las élites españolas que se dedicaron a actividades ligadas al agro como el establecimiento de haciendas, actividades rentistas de alquiler de tierras, concentración de tierras, el cual implicó vivir de una economía parasitaria ligada a patrones de comportamiento señorial aristocrático, como una forma de mostrar a las diversas castas el poder político y social de dicha élite, por otra parte, los indígenas y mestizos que se desarrollaron en el campo del comercio, producción, minería, entre los más importantes, todos ellos articulados por el gran flujo comercial entre los diversos virreinatos de España en el continente americano y por el comercio de la plata que era el activo principal entre América y Europa (Kláren, 2004).

Tanto la colonia como la naciente república peruana se configuraron dentro de una economía capitalista dependiente, productora de materias primas con bajo o nulo valor agregado, ligados a la superexplotación de los centros globales afectando el desarrollo del pueblo peruano sin trabajo calificado y con bajos niveles de ingresos.

[...]. El hecho de que la estructura social básica de los países pobres es la estructura colonial o dependiente. Este hecho afecta el desarrollo del capitalismo en todas las regiones donde se da, y por lo tanto afecta la estructura de las clases sociales y el papel que éstas juegan en la sociedad y la política. No es lo mismo que el capitalismo surja en un país dominante o en un país dependiente, que surja en un país que explota a otro país o en un país que es explotado por otro país (Gonzales, 2006, p. 209).

La naturaleza del capitalismo dependiente del Perú a los centros globales, es expresado en su rol de productor de materias primas como resultado de su configuración histórica del colonialismo y explotación y su rol "asignado" en la división internacional de trabajo en los últimos quinientos años, que no solo ha influenciado la estructura mono exportadora de materias primas, (elemento fundamental que determina su crecimiento económico) sino también en la situación económica y empresarial, que se expresa en una mayor participación económica de las trasnacionales y los flujos internacionales de capital concentradas en la materias primas y la poca presencia de las micro empresas peruanas en la economía, elementos que en conjunto no permiten un progreso económico estable (Lust, 2018).

\section{EL CONTRATO COLONIAL Y EL GÉNERO}

La otra parte integrante del contrato colonial es el contrato sexual, que es la subordinación de la mujer al varón, idea que ha sido legitimada en toda la tradición occidental, desde los filósofos clásicos de la Grecia antigua hasta los pensadores contemporáneos de Europa y Occidente (Amorós, 1991).

El contrato social clásico, se centra en los intereses del hombre, en especial el varón, dicha concepción es seguida por Hobbes, Locke y Rousseau, que consideran al varón 
como un sujeto solipsista autosuficiente y por el cual las mujeres estarían relegadas a las tareas del hogar, reproducción, sexo, cuidado e idealización de belleza, asimismo, con el contrato social los varones crean una fraternidad que les da el título de maridos, trabajadores y ciudadanos, y que excluyeron a las mujeres de cualquier participación en la esfera pública (polis), relegándoles a la esfera privada, especialmente a la casa (Oikos), el contrato social opera bajo la ilusión de considerar a todos los sujetos iguales con los mismo deberes y derechos y que la sociedad civil y el Estado son las máximas expresiones de organización social de la humanidad, pero, en realidad es solo una idealización ya que excluye a muchos sujetos entre ellos las mujeres, tanto en el mundo occidental como nooccidental (Pateman, 1995).

En el Perú, el contrato colonial, tiene una vertiente de contrato sexual, que implica la dominación del varón sobre la mujer y esto como producto de la colonización española del cual hemos heredado un sistema de patriarcalismo imbricado con la religión cristiana, en otras palabras, un patriarcalismo cristiano-céntrico (Grosfoguel, 2013). Al respecto, Mannarelli (2018) explica cómo estaba subordinada la mujer en la colonia:

Las relaciones entre marido y mujer en la sociedad estamental, como la mayoría de estas, estuvieron formalmente definidas. El marido tenía derecho sobre el cuerpo de su esposa como señor y cabeza de ella. Los tratadistas de la época advertían que la esposa no debía ser tratado como esclava, sino como compañera y hermana de cuidados y vida. Sin embargo, tanto el derecho civil como el canónico insistieron en que el "marido como legítimo" y verdadero superior" podían castigar moderadamente a su mujer (p. 38).

En el Perú, como en otras partes del mundo las mujeres occidentales jugaron también un papel muy importante dentro de la colonización y de la estructura patriarcal cristiano-céntrica, ya que ellas sufrían y reproducían esas jerarquías de dominación, así era el caso de las mujeres españolas que reproducían el ethos europeo en tierras americanas y organizaban el trabajo de la servidumbre, teniendo a su cargo, indígenas y esclavos africanos (Mannarelli, 2018).

El dominio del patriarcalismo cristiano-céntrico en el Perú y Latinoamérica fue institucionalizado a través del contrato sexual, el cual ha normalizado el dominio del varón sobre la mujer, pero debemos tener en cuenta que aquellas mujeres que tenían el estatus de género de mujer eran las mujeres blancas occidentales/europeas, las cuales eran tratadas en términos figurativos de naturaleza a explotar o infantes a ser tuteladas, mientras que las mujeres no europeas no compartían dicho estatus, de ahí que ellas eran llamadas hembras, es decir, eran una versión inferior de las mujeres, con un estatus de bestias, lo que representa el lado oculto del sistema de género (Lugones, 2008).

La estructura de la sociedad colonial del Perú fue heredada en la naciente república peruana, de ahí que las mujeres criollas tenían cierto margen de actuación, aunque dominadas por los varones, distinto fue el caso de las mujeres no-europeas que sufrían una multiplicidad de relaciones de dominación, negando o restringiendo sus derechos políticos, económicos, sociales y subordinadas al poder del patriarcalismo cristianocéntrico, expresadas en el Estado y las leyes peruanas, la sociedad, la cultura, educación, entre otros campos (Mannarelli, 2018). 


\section{EL CONTRATO COLONIAL Y EL EUROCENTRISMO}

El contrato colonial tiene una componente epistémica, el cual legitima y refuerza el capitalismo, racismo y patriarcalismo, para ello el eurocentrismo juega un rol de ideología en Occidente (Amin, 1989), que promueve la idea de superioridad de Europa frente al resto de pueblos del mundo. El máximo exponente del eurocentrismo en la filosofía fue Hegel (1980) quien sostenía: "La historia universal va de Oriente a Occidente. Europa es absolutamente el término de la historia universal. Asia es el principio” (p. 201). Entre las narrativas de superioridad europea están las categorías como racionalidad, ciencia, secularismo, capitalismo, democracia, derechos humanos, entre otros (Grosfoguel, 2006). Al respecto, Blaut (1993) afirma:

[Eurocentrismo]. Esta palabra es una etiqueta para todas las creencias que postulan la superioridad pasada o presente de los europeos sobre los no europeos (y sobre las personas minoritarias de ascendencia no europea). [...] la parte realmente crucial del eurocentrismo no es una cuestión de actitudes en el sentido de valores y prejuicios, sino más bien una cuestión de ciencia, erudición, y opinión informada y experta. Para ser precisos, el eurocentrismo incluye un conjunto de creencias que son declaraciones sobre la realidad empírica, declaraciones que los europeos educados y usualmente desprejuiciados aceptan como verdaderas, como proposiciones apoyadas por "los hechos" (pp. 8-9).

El Eurocentrismo consiste en concebir, producir, distribuir e institucionalizar el conocimiento científico, social y humanístico tomando como referencia la experiencia histórica, política, social, económica y cultural de Europa, negando los conocimientos de todas las exterioridades no-europeas, todo esto como producto de la colonialidad que lo constituyó como eje de del sistema mundo-moderno/colonial a partir de 1492 (Dussel, 2008a). El contrato social tiene como referente histórico primero a Europa Occidental y después a los Estados Unidos, siendo referentes de la filosofía política y la constitución del Estado moderno, dicha visión es avalada por el eurocentrismo que superioriza la experiencia histórica del mundo occidental e inferioriza e invisibiliza el mundo nooccidental al considerar que la experiencia histórico social y epistémico fuera de Occidente son expresiones premodernas, inferiores y bárbaras (Grosfoguel, 2013).

En el Perú hemos asimilado a la epistemología occidental como el único conocimiento válido para explicar todos los campos del saber, sobre todo en la Filosofía, la Ciencia Política, el Derecho, etc., que son importantes para entender la teoría del contrato social y los fundamentos de la República. La universidad occidental/occidentalizada es parte de la estructura global de dominación epistémica, la universidad en América Latina y el Perú sirvió para silenciar e invisibilizar los conocimientos de los vencidos y asumir como verdades absolutas y legítimas el saber occidental, creando una inferioridad en las poblaciones conquistadas, racializadas y empobrecidas (Mejía, 2020).

La universidad peruana en los tiempos de la colonia cimentó la colonialidad del saber, ya que adecuó su contenido epistémico a los saberes cristianos de los conquistadores europeos, condenando a la exclusión e invisibilización los saberes nativos, apoyando la represión de las espiritualidades de las poblaciones indígenas y fomentando 
el pensamiento único occidental como superior a las epistemes indígenas y haciendo que los dominados aceptasen su inferioridad como algo natural (Germana, 2018). En relación a este tema, Mejía (2020) sostiene:

La universidad era el campo de la reproducción de la colonialidad, El privilegio aristocrático de la educación implicaba la distinción de la casta blanca-criolla y la exclusión indígena ejercida por medio del acceso y el control directo de las personas. Al principio, se utilizaría el discurso de la "sangre limpia" y los saberes y practicas eclesiásticas del cuidado de las almas de los primeros siglos de la conquista; desde el siglo XVIII, se acentuaría el sometimiento de los cuerpos racializados mediante el dominio o oligárquico-criollo y la retórica de las "buenas costumbres" y las prácticas “civilizadas” (pp. 171-172).

\section{EL CONTRATO COLONIAL EN LA REPÚBLICA}

La naciente república peruana estaba ligada a las concepciones y prácticas del periodo colonial, razón por la cual el nuevo orden político no significó un cambio, sino la continuación de esta, ya que nunca superó la herencia colonial desde su fundación (Lynch, 2014). Asimismo, el nuevo contrato social, no implicó una transformación importante en la sociedad peruana, pues valores como la libertad, igualdad y en parte la propiedad que son centrales en la teoría del contrato social (Rousseau, 1980) no llegaron a aplicarse, por el contrario el Estado criollo comportaba elementos ideológicos liberales como la adopción de la forma republicana, gobernantes representativos, derechos civiles y políticos, pero para una minoría de descendiente de españoles, por otra parte, elementos conservadores se hacían también presente, como el reconocimiento de la importancia de la familia y la Iglesia Católica en la formación del Perú, en ese sentido las élites liberales y conservadores tenían algunos puntos en común como la visión aristocrática de la nueva sociedad "republicana” (Klarén, 2004).

La república peruana del siglo XIX se configuró bajo los cimientos del Virreinato, privilegiando a los descendientes europeos, los criollos, (blancos, varones, heterosexuales, burgueses), como ciudadanos de plenos derechos, excluyendo a mestizos, indígenas, mujeres, afrodescendientes y manteniendo las estructuras, concepciones y prácticas políticas, económicas, sociales y culturales de la colonia en todo el periodo republicano, asimismo, la república estuvo a cargo de las élites criollas tanto liberales como conservadoras, el cual continuaron excluyendo a la gran mayoría de peruanos, y que se reflejó en la poca participación en los gobiernos de turno, las elecciones y el diseño de las constituciones políticas (Klaren, 2004; Lynch, 2014; Rubio, 2014).

La dominación colonial de tres siglos (colonialismo externo) dejó una fuerte impronta cultural en la sociedad peruana, manifestándose así el colonialismo interno, que es aquel fenómeno que históricamente está conectado con el pasado colonial de dominación de una nación, por el cual la nueva clase política dominante (los criollos) adopta la relaciones y estructuras de dominación anterior, asimismo, el colonialismo interno se caracteriza por la desigualdad estructural que sufren las poblaciones originarias (carecen territorio, representación jurídica propia, poder y participación política, ejército, economía) frente a las élites europeizadas, dichas poblaciones o naciones son racializadas e inferiorizadas dentro del Estado-Nación, en lo mejor de los casos la identidad indígena 
es usada demagógicamente como símbolo liberador, en ese sentido, las poblaciones originarias o naciones colonizadas por el Estado-nación "moderno" sufren las mismas relaciones de dominación del colonialismo internacional (González, 2003).

El colonialismo interno ha sido practicado por las élites criollas, el cual han mantenido la estructura jerárquica sociedad colonial, subalternizando a todos los sectores de la sociedad, la república criolla continuó expandiendo las lógicas civilizatorias de Occidente en el resto del país, para los criollos, en los andes vivían los "indios semicivilizados y en la selva los salvajes a civilizar, en ese sentido, la colonización de la selva por parte de la republicana peruana empezó a mediados del siglo XIX (y aún continua) con las nuevas actividades extractivas como caucho, petróleo, gas, tala y minería ilegal (Morel, 2014) y la colonización de las almas por parte de la iglesia católica siguiendo los viejos discursos de civilización y barbarie, pero en el siglo XX (Dávila, 2021).

El colonialismo interno ha sido parte de la historia independiente y republicana del Perú, como en gran parte de Latinoamérica (Soria, 2009; González, 2003), el cual ha creado una escisión entre las élites dominantes criollas costeras respecto al mundo andino y amazónico, estos últimos subsumidos en la pobreza y el subdesarrollo, manifestación de ello ha sido el latifundismo, gamonalismo y esclavismo en gran parte del siglo XIX y $\mathrm{XX}$, las migraciones del campo a la ciudad a mediados del siglo XX, informalidad económica, la violencia política y el electorado antisistema en las elecciones.

La independencia del Perú no llegó a crear una unidad nacional, que expresase una síntesis de todo el pueblo peruano, por el contrario, esta se constituyó como distinción y separación (Castro, 2018), para ser más precisos, se creó una sociedad con marcadas clases sociales, raciales, de género, de conocimiento, entre otros. La independencia del Perú no llevó a la formación de una nación inclusiva, con una comunidad con los mismos derechos y deberes y con un destino en común, por el contrario, esta se asentó sobre estructuras coloniales, como el racismo, ciudadanía estratificada, el abandono y desprecio al indígena. $\mathrm{Al}$ respecto, Portocarrero (2015) sostiene:

En el Perú, el racismo y el orden colonial continúan marcando la vida cotidiana pese a la legalidad republicana y la consagración formal del principio de igualdad de derechos. Entonces, el sentimiento de conciudadanía, que lleva a respetar al otro como una persona que tienen los mismos derechos que yo, es aún débil. La solidaridad y la fraternidad son también actitudes que no están incorporadas en la conciencia de los peruanos (p.19).

En el periodo republicano, y en especial a partir de mediados del siglo XIX y producto de la colonialidad del saber, las ideas europeas del racismo científico fueron importadas al Perú configurándose un racismo con discursos de carácter fenotípico o fisiognómico, que en esencia era un racismo que se apoyaba en principios científicos que postulaba las ciencias naturales, la biología y la antropología, los postulados del racismo científico permearon toda la sociedad, Estado, instituciones, leyes, influenciando en las subjetividades, el modo de sentir y percibir de la población general. Entre los antecesores del racismo científico está el gobierno de Ramón Castilla que desarrolló políticas de promigración europea, en especial la migración alemana, el cual se consideraba como una población laboriosa, educada y creativa. Otro de los exponentes fue Clemente Palma, hijo 
de Ricardo Palma y que será el difusor de las ideas de Gustavo Le Bon (Zapata y Rojas, 2013).

La difusión de las ideas raciales de corte científico se difundió a través de la sociología positivista europea, en el contexto después de la guerra con Chile, en el cual el tema al debate giraba en torno al indio, el cual representaba la degeneración de la raza para las élites criollas y también por la historia de violencia y opresión y por la importancia demográfica (Obregón, 2019).

El racismo en el periodo republicano ha beneficiado a las personas blancas (élites criollas) configurándose el privilegio blanco como una categoría que permite que las personas blancas experimenten ventajas sociales, económicas políticas por sus características físicas, el cual les permite mejorar su estatus social, posición económica y gozar de una posición de superioridad en la sociedad, el ejercicio de dicho privilegio puede ser consciente o inconsciente (Balcazar, 2011).

\section{HACIA UNA UTOPÍA TRANSMODERNA}

Los teóricos de la modernidad/Colonialidad plantean la transmodernidad como un nuevo horizonte utópico para superar los límites de la provincialidad moderna, en otras palabras, generar un dialogo intercultural e interepistémico entre todas las experiencias históricas negadas e invisibilizadas por la modernidad, el cual comprenden todas las otredades de Occidente (mundo latino, islámico, africano, chino, hindú, etc.) y que pueden responder a los problemas no resueltos por Occidente, pero desde sus propios locus enunciativos, cuestionando y reinterpretando una nueva hermenéutica y praxis política (Dussel, 2015). Respecto a la transmodernidad, Grosfoguel (2008a) sostiene:

[Es] un diálogo horizontal liberador, en oposición al monólogo vertical de Occidente, requiere de una descolonización en las relaciones globales de poder. No podemos asumir el consenso habermasiano o las relaciones horizontales de igualdad entre las culturas y los pueblos cuando a nivel global están divididos en los dos polos de la diferencia colonial. Sin embargo, podemos comenzar a imaginar mundos alternativos más allá de la disyuntiva eurocentrismo versus fundamentalismo.

Transmodernizar las categorías políticas de la modernidad implica descolonizar y replantear las categorías políticas de la modernidad desde otros horizontes periféricos (Grosfoguel, 2008a; Dussel, 2015). La descolonización de las categorías políticas de la modernidad permitirá fundar una República, democrática, plural y transmoderna, para ello debemos empezar a cuestionar el lado negativo de la modernidad, vale decir, la colonialidad y todos los aparatos de dominación del sistema mundo moderno/colonial (Mignolo, 2010; Grosfoguel, 2013; Dussel, 2015). La descolonización permitirá proponer un nuevo tipo de contrato social, Estado, ciudadanía y democracia, de esa forma terminar con las desigualdades estructurales y proponer un horizonte político al Perú y Latinoamérica, creando una sociedad más justa y solidaria con instituciones políticas más genuinas y representativas para las grandes mayorías excluidas del país.

\section{CONCLUSIONES}

La modernidad europea constituyó la civilización occidental desde 1492, proyecto que fue expandiéndose por todo el mundo a través de la colonización global por parte de 
los imperios europeos, dando origen así al sistema-mundo moderno/colonial y teniendo al continente americano como primer referente para dicha empresa. El continente americano fue escenario donde surgió la filosofía moderna, la clasificación ontológica del mundo y la nueva división internacional del trabajo teniendo al racismo como principal principio organizador de todas las relaciones de dominación.

A doscientos años de la independencia del Perú y del nacimiento de la república, las relaciones de dominación colonial siguen manteniéndose presentes en la sociedad peruana, la república no se fundó sobre un contrato social con sujetos iguales y con derechos y deberes recíprocos que formasen una comunidad nacional, por el contrario, el Perú independiente se fundó sobre el contrato colonial, que tiene fundamento en las relaciones de dominación formal e informal entre colonizador y los colonizados y que organizan la vida política, económica, social, cultural y epistémico en los territorios dominados, dichas relaciones trascienden la independencia política de los antiguos territorios coloniales.

Con la independencia del Perú, las relaciones de dominación entre el colonizador y los colonizados adquieren la categoría de colonialidad, que es un conjunto de relaciones de dominación que superan la dominación política-legal de las antiguas administraciones coloniales, en este nuevo periodo, la relaciones de dominación política, económica, social, cultural, epistémica se siguen manteniendo, su continuidad es ejecutada por las élites euro descendientes (criollos) que gozan del privilegio blanco y continúan reproduciendo dichas relaciones de dominación a través del colonialismo interno, donde se sigue considerando solo a los descendientes europeos, los criollos (blancos, varones, heterosexuales, burgueses y citadinos) como ciudadanos de plenos derechos, excluyendo a los mestizos, indígenas, afrodescendientes, mujeres entre otros, como sujetos inferiorizados dentro de la nueva república.

En suma, es menester que la filosofía política reflexione y de respuestas a los problemas heredados por la modernidad como es la colonialidad en todas sus expresiones de dominación, entre ellas el contrato colonial que han marcado nuestro derrotero en los últimos cinco siglos de nuestra historia y que ha influido en el devenir de la república, sociedad y ciudadanía, lo que ha contribuido a la desestructuración del Perú en dos mundos, el mundo criollo, occidental, moderno civilizado, desarrollado y el otro indígena, tradicional, pre-moderno, bárbaro, y subdesarrollado, dicha división histórica no ha permitido crear una comunidad nacional, por el contrario, hemos sido subsumidos en divisiones y guerra fratricidas que no nos ha permitido crear un camino propio como sujeto histórico en el mundo.

\section{ORCID} Perú

Jonathan Riveros Ramos: Universidad Nacional Mayor de San Marcos, Lima,

\section{FUENTE DE FINANCIAMIENTO}

El estudio fue autofinanciado. 


\section{CONFLICTOS DE INTERÉS}

El autor declara que no existe conflicto de interés.

\section{AGRADECIMIENTO}

No aplica.

\section{PROCESO DE REVISIÓN}

Este estudio ha sido revisado por pares externos en modalidad de doble ciego.

\section{DECLARACIÓN DE DISPONIBILIDAD DE DATOS}

No aplica.

\section{REFERENCIAS BIBLIOGRÁFICAS}

Aguilar García, E. G. (2018). Rastreando el origen de las estructuras del conocimiento occidental fundadas en el racismo epistémico. Hacia una nueva propuesta para la descolonización del pensamiento. Revista de Filosofía Praxis, (77), pp. 1-23. DOI: https://doi.org/10.15359/77.2

Albán Achinte, A. (2010). Comida y colonialidad. Tensiones entre el proyecto hegemónico moderno y las memorias del paladar. Calle14, 4(5), pp. 10-23. DOI: https:// doi.org/10.14483/21450706.1200

Alvarado, J. (2017). Investigación filosófica en perspectiva decolonial. Revisa electrónica de humanidades, educación y comunicación social, 23(2). pp. 236-252. Recuperado de http://ojs.urbe.edu/index.php/redhecs/article/view/711/642

Amin, S. (1989). El Eurocentrismo. Critica de una ideología. México: Siglo Veintiuno Editores.

Amorós, C. (1991). Hacia una crítica de la razón patriarcal. 2ed., Barcelona: Ed. Anthropos.

Auat, A. (2011). Hacia una política situada. Buenos Aires: Waldhuter Editores.

Balcazar, F. E., Berardi, L. y Taylor-Ritzler, T. (2011). El "privilegio de los blancos": otra fuerza de dominación social de las clases privilegiadas. Espacios en Blanco. Revista de Educación, 21(1) pp. 85-110. https://www.redalyc.org/ pdf/3845/384539803 004.pdf

Barriendos, J. (2011). La colonialidad del ver. Hacia un nuevo diálogo visual interepistémico. Nómadas, (35), pp. 13-29. https://www.redalyc.org/articulo.oa?id $=105122653002$

Blaut, J.M. (1993). The colonizer's model of the world. Geographical Diffusionism and Eurocentric History. New York: The Guilford Press.

Benjamin, W. (2008). Tesis sobre la historia y otros fragmentos. México: Ed. Itaca

Benyera, E. (2020). Breaking the Colonial "Contract": From Oppression to Autonomous Decolonial Futures. Reino Unido: Ed. Lexington Books. 
Castro, A. (2018). Una modernidad diferente. En: Rueda, E. \& Villavicencio, S. (Eds.). Modernidad, colonialismo y emancipación en América Latina. (pp. 55-69). Ciudad Autónoma de Buenos Aires: CLACSO.

Castro-Gómez, S. (2007). Decolonizar la universidad. La hybris del punto cero y el diálogo de saberes. En: Castro-Gómez, S., y Grosfoguel, R. (Eds.). "El giro decolonial. Reflexiones para una diversidad epistémica más allá del capitalismo global”. (pp. 7991). Bogotá: Siglo del Hombre Editores; Universidad Central, Instituto de Estudios Sociales Contemporáneos y Pontificia Universidad Javeriana, Instituto Pensar.

Césaire, A. (1979). Discurso sobre el colonialismo. México: UNAM.

Dávila Francia, J. T. (2021). Los dominicos y los pueblos indígenas de Madre de Dios: estudio documentario. Arqueología y Sociedad, (34), pp. 225-239. DOI: https://doi.org/10.15381/arqueolsoc.2021n34.e20628

De Sousa Santos, B. y Meneses, M. P. (2014). Epistemologías del Sur. Perspectivas. Madrid: Ed. Akal.

Dussel, E. (2015). Filosofías del Sur. Descolonización y transmodernidad. México D.F.: Ed. Akal.

Dussel, E. (2008a). 1492 El encubrimiento del otro. Hacia el origen del "Mito de la modernidad”. Bolivia: Ed. Vicepresidencia del Estado Plurinacional de Bolivia.

Dussel, E. (2008b). Marx y la modernidad. Conferencias de la Paz. Bolivia: Rincón ediciones

Dussel, E. (2007). Política de la Liberación. Historia mundial y crítica. Madrid: Ed. Trotta.

Dussel, E. (2005). Origen de la filosofía política moderna: Las Casas, Vitoria y Suárez (1514-1617). Caribbean Studies, 33(2), pp. 35-80. https://www.redalyc.org/ pdf/392/39233204.pdf

Dussel, E. (2000). Europa, modernidad y eurocentrismo. En: Lander, E. (Ed.) La colonialidad del saber: eurocentrismo y ciencias sociales. Perspectivas latinoamericanas. (pp. 41-53). Buenos Aires: CLACSO.

Dussel, E. (1980). Filosofía de la Liberación. Bogotá: Universidad Santo Tomás - Centro de Enseñanza Desescolarizada.

Escobar, A. (2011). Epistemologías de la naturaleza y colonialidad de la naturaleza. Variedades de realismo y constructivismo. En: Montenegro Martínez, L. (Ed.) Naturaleza Cultura y aproximaciones a propósito del bicentenario de la independencia de Colombia. (pp. 50-72). Bogotá: Jardín Botánico de Bogotá y José Celestino Mutis.

Fanon, F. (2009). Piel negra, máscaras blancas. Madrid: Ed. Akal.

Foucault, M. (2004). Nietzsche, la Genealogía, la Historia. $5^{\circ}$ ed., Valencia: Ed. Pre-textos.

Foucault, M. (2019). Microfísica del poder. Ciudad Autónoma de Buenos Aires: Siglo Veintiuno Editores Argentina. 
Gandarilla Salgado, J. G. y Gómez Arredondo, D. (2017). Estado-nación y colonialidad del poder en el pensamiento de Anibal Quijano. Crítica Jurídica/Nueva época, 18, pp. 51-67. https://www.crim.unam.mx/web/sites/default/files/6.\%20Estadonaci $\% \mathrm{C} 3 \% \mathrm{~B} 3 \mathrm{n} \% 20 \mathrm{y} \% 20$ colonialidad $\% 20 \mathrm{del} \% 20$ poder.pdf

Garzón López, P. (2018). Colonialidad jurídica. Eunomia. Revista en cultura de la legalidad, 14, pp. 206-214. DOI: https://doi.org/10.20318/eunomia.2018.4164

Germaná, C. (2018). Colonialidad/descolonialidad de la Universidad peruana. Pluriversidad, (1), pp. 25-40. https://revistas.urp.edu.pe/index.php/pluriversidad/ article/ view/1666/1523

González Casanova, P. (2006). Sociología de la explotación. Buenos Aires: Consejo Latinoamericano de Ciencias Sociales (CLACSO).

González Casanova, P. (2003). Colonialismo Interno (una redefinición). Revista Rebeldía, (12), pp. 2-30. Recuperado de http://conceptos.sociales.unam.mx/conceptos_ final/412trabajo.pdf

Grosfoguel, R. (2016). Caos sistémico, crisis civilizatoria y proyectos descoloniales: pensar más allá del proceso civilizatorio de la modernidad/colonialidad. Tabula Rasa. (25), pp. 153-174. DOI: https://doi.org/10.25058/20112742.79

Grosfoguel, R. (2014). Las múltiples caras de la islamofobia. De Raíz Diversa. Revista Especializada en Estudios Latinoamericanos 1 (1), pp. 83-114.

Grosfoguel, R. (2013). Racismo/sexismo epistémico, universidades occidentalizadas y los cuatro genocidios/ epistemicidios del largo siglo XVI. Tabula Rasa, (19), pp. 31-58. DOI: https://doi.org/10.25058/20112742.153

Grosfoguel, R. (2012). El concepto de «racismo» en Michel Foucault y Frantz Fanon: ¿teorizar desde la zona del ser o desde la zona del no-ser?. Tabula Rasa, (16), pp. 79-102. DOI: https://doi.org/10.25058/20112742.112

Grosfoguel, R. (2008a). Hacia un pluri-versalismo transmoderno decolonial Tabula Rasa, (9), pp. 199-215. DOI: https://doi.org/10.25058/20112742.345

Grosfoguel, R. y Mignolo, W. (2008b). Intervenciones descoloniales: Una breve Introducción. Tabula Rasa, (9), pp. 29-37. DOI: https://doi.org/10.25058/ 20112742.337

Grosfoguel, R. (2006). La descolonización de la economía política y los estudios postcoloniales. Transmodernidad, pensamiento fronterizo y colonialidad global. Tabula Rasa, (4), pp. 17-48. DOI: https://doi.org/10.25058/20112742.245

Hegel, G.W.F. (1980). Lecciones sobre la filosofía de la historia universal. Madrid: Alianza Editorial.

Klarén P. F. (2004). Nación y sociedad en la historia del Perú. Lima: Instituto de Estudios Peruanos. 
León, C. (2012). Imagen, medios y telecolonialidad: hacia una crítica decolonial de los estudios visuales. Aisthesis, (51), pp. 109-123. DOI: http://dx.doi.org/10.4067/ S0718-71812012000100007

Lepe-Carrión, P. (2016). El Contrato colonial de Chile. Ciencia, racismo y nación. Quito: Ediciones Abya-Yala.

Lugones, M. (2008). Colonialidad y Género. Tabula Rasa, (9), pp. 73-101. DOI: https:// doi.org/10.25058/20112742.340

Lust, J. (2018). El Surgimiento de una economía capitalista de subsistencia en el Perú. PLURIVERSIDAD, (5), pp. 61 - 78. DOI: https://doi.org/10.31381/ pluriversidad.v0i5.3207

Lynch Gamero, N. (2014). Cholificación, república y democracia. El destino negado del Perú. Lima: Otra Mirada.

Maldonado-Torres, N. (2008). La descolonización y el giro decolonial. Tabula Rasa, (9), pp. 61-72. Recuperado de DOI: https://doi.org/10.25058/20112742.339

Maldonado-Torres, N. (2007). Sobre la colonialidad del ser: contribuciones al desarrollo de un concepto. En: Castro-Gómez, S. y Grosfoguel, R. (Eds.), El giro decolonial Reflexiones para una diversidad epistémica más allá del capitalismo global. (pp. 127167). Bogotá, Colombia: Siglo del Hombre Editores; Universidad Central, Instituto de Estudios Sociales Contemporáneos y Pontificia Universidad Javeriana, Instituto Pensar.

Mannarelli, M. (2018). La domesticación de las mujeres. Patriarcado y género en la historia peruana. Lima, Perú. Ed. La Siniestra Ensayo.

Marx, K. (1988). El Capital. Crítica de la economía política. El proceso de producción de capital. (Vols. I, II y III). México: Siglo XXI editores.

Mejía Navarrete, J. (2020). Modernidad, sociedad y colonialidad. Ensayos desde el Perú. Lima: Fondo Editorial Facultad de Ciencias Sociales.

Mignolo, W. D. (2015). Habitar la frontera: sentir y pensar la descolonialidad (Antología, 1999-2014). Barcelona: Barcelona Centre for International Affairs, (CIDOB) y Universidad Autónoma de Ciudad Juárez (UACJ).

Mignolo, W. (2010). Desobediencia epistémica: Rétorica de la modernidad, lógica de la colonialidad y gramática de la descolonialidad. Argentina: Ediciones del signo.

Mills, Ch. W. (1997). The Racial Contract. Estados Unidos de América: Cornell University Press.

Montañez Pico, D. (2015). Contractualismo colonial y pueblos indígenas en la américa hispana Un pluralismo jurídico y político efectivo al orden. Clivajes. Revista de Ciencias Sociales, 2(4), pp. 106-130. https://clivajes.uv.mx/index.php/Clivajes/ article/view/1747/3185

Morel Salman, J. (2014). De una a muchas Amazonías: Los discursos sobre la "la selva". 
En: Barrantes, R. y Glave, M. (Eds.). Amazonía peruana y desarrollo económico. (pp. 21 46). Lima: GRADE e Instituto de Estudios peruanos (IEP).

Pateman, C. (1995). El contrato sexual. Barcelona, España: Ed Anthropos.

Portocarrero, G. (2015) La urgencia por decir "nosotros". Los intelectuales y la idea de nación en el Perú republicano. Lima: Fondo editorial de la Pontificia Universidad Católica del Perú (PUCP).

Quijano, A. Colonialidad del poder y clasificación social. En: Quijano, A. (2014). Cuestiones y horizontes: de la dependencia histórico-estructural a la colonialidad/descolonialidad del poder. Buenos Aires: CLACSO.

Obregón Hilario, W. A. (2019). El porvenir de las razas: el racialismo en el Perú entre los siglos XIX y XX. Análisis, 51(94), pp. 81-100. Recuperado de https://www.aacademica.org/alejandro.obregon/5.pdf

Ochoa Muñoz, K. (2014). El debate sobre las y los amerindios: Entre el discurso de la bestialización, la feminización y la racialización. El Cotidiano, (184), pp. 13-22. https://www.redalyc.org/pdf/325/32530724005.pdf

Restrepo, E. (2016). Descentrando a Europa: aportes de la teoría postcolonial y el giro decolonial al conocimiento situado. Revista Latina de Sociologia (RELASO), 6(1) pp. 60-71. DOI: https://doi.org/10.17979/relaso.2016.6.1.1965

Rousseau, J.J. (1980). Del Contrato Social. Discurso sobre las ciencias y las artes. Discurso sobre el origen y los fundamentos de la desigualdad entre los hombres. Madrid: Alianza Editorial.

Rubio, M. (2014). El legado vigente de los viejos liberales políticos. Lima: Fondo Editorial de la Pontificia Universidad Católica del Perú

Salazar Bondy, A. (1995). Dominación y liberación: Escritos 1966-1974. Lima: Fondo Editorial de la Facultad de Letras y Ciencias Humanas UNMSM.

Soria Choque, V. (2009). Colonización mental: mecanismos de adaptación y fragmentación psicológica del andino-mestizo. Revista de Investigación Psicológica, (5), 85-94. http://www.scielo.org.bo/scielo.php?script= sci_arttext\&pid=S2223-0322009000100009

Thompson, E. (2000) Colonial Citizens: Republican Rights, Paternal Privilege, and Gender in French Syria and Lebanon. Nueva York: Columbia University Press.

Toulmin, S. (2001). Cosmópolis. El trasfondo de la Modernidad. Barcelona: Ediciones Península S.A.

Veronelli, G. A. (2016). Sobre la colonialidad del lenguaje. Universitas Humanística, (81), pp. 33-58. DOI: 10.11144/Javeriana.uh81.scdl

Walsh, C. (2008). Interculturalidad, plurinacionalidad y decolonialidad: Las insurgencias político-epistémicas de refundar el Estado. Tabula Rasa, (9), pp. 131-152. https:// revistas.unicolmayor.edu.co/index.php/tabularasa/article/view/1498 


\section{Universidad Nacional Autónoma de Huanta}

Wallerstein, I. (2007). El universalismo europeo. El discurso del poder. México: Siglo XXI Editores.

Wallerstein, I. (2005). Análisis del sistema-mundo. Una introducción. México: Siglo XXI editores.

Zapata, A. y Rojas, R. (2013). ¿Desiguales desde siempre? Miradas históricas sobre la desigualdad. Lima: Instituto de Estudios Peruanos.

\section{CITAR COMO:}

Riveros Ramos, J. (2022). El contrato colonial y la fundación de la república peruana: un análisis decolonial. Puriq, 4, e244. https://doi.org/10.37073/puriq.4.1.244 